\title{
Explanations of Meaningful Actions
}

\section{Mantzavinos}

\begin{abstract}
There is a long tradition in philosophy and the social sciences that emphasizes the meaningfulness of human action. This tradition doubts or even negates the possibility of causal explanations of human action precisely on the basis that human actions have meaning. This paper provides an argument in favour of methodological naturalism in the social sciences. It grants the main argument of the Interpretivists, i.e. that human actions are meaningful, but it shows how a transformation of a "nexus of meaning" into a "causal nexus" can take place, proposing the "successful transformation argument".
\end{abstract}

Keywords: Meaning; Action; Explanation; Verstehen; Interpretation; Naturalism

Published in: Philosophy of the Social Sciences, vol. 42, 2012, pp. 224-238 https://doi.org/10.1177/0048393110392590 


\section{Introduction}

One of the oldest and most enduring debates in the philosophy of the social sciences is among Naturalists and Interpretivists. Both camps agree that a central point of the inquiry in the social sciences is human action; the point of disagreement concerns the issue of how human action should be approached and how it is to be studied by the social scientific disciplines (Geertz, 1973, Taylor, 1985, M. Salmon, 2003). Naturalists since Mill have argued that human actions have to be viewed as natural phenomena on a continuum with other phenomena in nature and that they should thus be studied accordingly. A distinct method for studying human actions as they occur in the social world is not thought to be necessary, and the social sciences are not regarded as having any special status within the spectrum of scientific disciplines. Interpretivists since Dilthey and Collingwood, by contrast, have argued that human actions cannot be viewed as natural phenomena since being endowed with meaning makes them categorically distinct. Verstehen or understanding is thought to be the appropriate method for studying human actions as they occur in the social world, and the social sciences are assigned a special status on the spectrum of scientific disciplines.

This debate has a number of different facets, the most important being the ontological and the methodological ones. Naturalists usually argue that human actions are natural phenomena; they also argue that they can be apprehended by the method of the natural sciences. Interpretivists usually argue that human actions are not natural phenomena proper, and they should thus be apprehended by a distinct method. In this paper I will not deal with the arguments on ontology, but will only discuss the methodological aspect of the debate. I will present an argument in favour of a minimalistic methodological naturalism that I call the "successful transformation argument". This argument has five steps and aims to establish the 
claim that even if human actions are meaningful, they can still be causally explained. Let me turn to the five steps of the argument.

\section{The "Successful Transformation Argument"}

Step one: Human actions have meaning. Unstructured bodily movements are not human actions: pure physiological reactions are not constitutive of a human action. Everybody seems to agree on that. The disagreement concerns whether it is constitutive for a human action to have meaning or not. It has been a common strategy among Naturalists to argue that human actions just are events of the same kind as all natural phenomena and that, accordingly, they must be treated as such. Interpretivists on the other hand have argued that it is constitutive for human action that it has meaning - this is what differentiates it from being a bundle of physiological reactions or bodily movements. Interpretivists have rightly insisted on this point

- if one admits that human actions need not be meaningful, then the door is automatically opened for the battery of naturalistic arguments that are difficult, if not impossible, to countervail. Besides, there is a much stronger consequence - what clearly distinguishes human actions from rocks falling will apparently be obscured or lost and the grounds for any special science of human action undermined.

The first step of my argument is to grant this point to the Interpretivists and to assume that human actions have meaning, i.e. that human actions are meaningful events. What is it for an action to have meaning? Human action is endowed with meaning when the actor who is engaging in it interprets it against the background of his goals, his beliefs, and his other mental states while interacting with his natural and social environment; this is a complex process and can involve the conscious or unconscious use of symbols - though it need not. 
This nexus of meaning ${ }^{1}$, which arises in connection with a human action, can be accessed either from a first-person perspective or a third-person perspective, i.e. an observer's, perspective. From a methodological point of view it is important to inquire into how the access from the observer's perspective looks and how a description, a reconstruction, and (possibly) an explanation of a nexus of meaning can take place. In addition, it should be obvious that the information that the actor himself conveys (with the help of which the firstperson perspective is described and reconstructed) can of course be used to apprehend the nexus of meaning from an observer's perspective. So, a nexus of meaning arises in connection with every human action. This is the starting point.

Step two: Different ways of apprehending the nexus of meaning. In a second step, the question arises as to how a nexus of meaning can be apprehended, or in other words, as to what kind of a conceptual apparatus can be used in order to grasp a nexus of meaning. I am going to sketch very briefly four different influential approaches that in one way or another have provided a conceptual apparatus that tackles this issue. The aim is not to provide a thorough discussion of these approaches here, but only to show that there are in principle different ways of apprehension of the nexus of meaning of an action.

According to one influential view traced back to Max Weber, one way of apprehending the nexus of meaning of an action is to identify the motive of the action. One grasps the meaning of an action if one is able to state its motive. In the famous formulation of Weber (1922/1985, 550): "A 'motive' is a nexus of meaning which seems to the actor himself or to the observer to be an adequate 'reason' for the conduct in question."

\footnotetext{
${ }^{1}$ I use the term "nexus of meaning" because this is the term widely used both in the interpretivist tradition and by the critics of it. One example of an author in this tradition is Gadamer (1986/1993, p. 434) who speaks of "Sinnzusammenhang" which can best be translated as "the nexus of meaning" and of a critic Albert (1994, ch. 2).
} 
Another even more influential approach suggests that the nexus of meaning of an action can be apprehended if the intention of the action is identified. One has grasped the meaning of an action if one is able to state the intention of the actor. In short, stating that an action is meaningful simply reflects the intentional character of the action. John Searle and Daniel Dennett, among others, seem to suggest this approach. In Searle's account the concept of 'intention' is conceived very broadly as 'directedness', i.e. as the aspect of mental states by which they are directed to states of affairs in the world beyond themselves (2001, p. 34ff. and 2009). And in Dennett's "Theory of Intentional Systems" (1987) the intentional stance is developed as a strategy for describing a system in terms of beliefs, desires, and other intentional states. In the case of human agents the theory suggests that action should be presented with the help of an intentional vocabulary. According to the protagonists of this approach, the meaning of an action, thus, can adequately be apprehended if the respective intention or intentions are specified.

A third approach suggests that the nexus of meaning of an action is apprehended if one states the reasons for the action. The beliefs and desires of the agent are standardly referred to as the reasons for an action. Their specification can reveal the relevant nexus of meaning. This position is usually defended by reference to Donald Davidson's classic “Actions, Reasons and Causes" (1963/2001) and is often meshed with the intentionalist approach.

The common core of these three approaches is that they all offer a description of a human action by appealing to a few elements that stand in a one-to-one relationship with the action: motives, intentions, or reasons. They are to be classified as 'one-to-one theories of human action', since they fail to specify a mechanism that could more accurately depict the process of endowing meaning to an action. "The meaning of Anna's action - to cook a meal at seven o' clock in the evening - is that Anna wants to be a good mother"; "The meaning of Anna's 
action - to cook a meal at seven o' clock in the evening - is that Anna has the intention to be a good mother"; "The meaning of Anna's action - to cook a meal at seven o' clock in the evening - is that Anna has the belief that her action makes her a good mother and she has the desire to be a good mother." Each of these statements captures the meaning of the fact that Anna cooks a meal at seven o'clock in the evening by appealing to Anna's mental states without specifying a mechanism by which these mental states lead to the endowment of meaning on her action.

A fourth approach that does specify such a mechanism focuses on the rationality of the actor. According to this approach, the nexus of meaning of an action to be grasped is more complex. The actor avails of many goals that he orders in a ranking according to his preferences, and he chooses the course of action that he expects will improve his position. It has become a quite standard practice to use the vocabulary and the formal machinery of mainstream economic theory when theorizing on rationality (e.g. Becker, 1976) and to argue that action is the result of a conscious choice of a (more or less) well-informed individual who maximizes his utility given his preferences and the constraints of the environment that he is facing. However, we do not need to bother here with the different versions of the rationality postulate, since we are only concerned with the principle: rationality helps transform the beliefs and desires into a concrete decision, which then leads to an action ${ }^{2}$. Thus a more complex mechanism is depicted, which is supposed to grasp the meaning of an action in a more satisfactory way: “The meaning of Anna's action - to cook a meal at seven o' clock in the evening - is that, while Anna would rather go to the cinema or for a walk, these options appear less attractive to her in the face of her goal of being a good mother, and thus she has decided to cook a meal something that is a rational decision given her options, her preferences, and her knowledge of circumstances."

\footnotetext{
${ }^{2}$ For a discussion of the rationality postulate see for example Mantzavinos (2001, ch. 4) and Boudon (2003).
} 
The main point of this step of the argument is, thus, that there is a range of different ways of apprehending a nexus of meaning. There is, at least in principle, no limit in the diversity of the conceptual apparatuses that can be used in order to describe a nexus of meaning. The authors in the interpretivist tradition have indeed made use of many different conceptual frameworks and the "successful transformation argument" does not depend on and is compatible with this diversity.

Step three: Regularity of nexuses of meaning. The second step of the argument has shown that, from an observer's perspective, there are a number of different approaches and thus a number of different possible ways to convey the nexus of meaning. These different approaches identify different 'fundamental elements' in the nexuses of meaning, i.e. elements whose identification and description turn a piece of behaviour into a meaningful action. With 'fundamental elements' I mean all the relevant mental states of the actor as well as all relevant mechanisms that are at work when a meaningful action is performed.

One could prima facie argue that a nexus of meaning could be transformed into a causal nexus in a straightforward way. In the classic paper of Davidson (1963/2001) briefly mentioned above, the claim is that the reasons for an action can serve as the causes of the action. The basic approach taken there is a transformation of the reasons as the 'fundamental elements' of a nexus of meaning, i.e. of the elements that make a piece of behaviour a meaningful action, into a causal nexus. His claim is that such reasons could be causes even if we could not come up with any generalizations that link the having of a reason and an action (this is the position of "anomalous monism"). This claim can be easily supported by the large literature on singular causation in philosophy of science which makes the case that causal explanations should be perfectly acceptable as genuine explanations even when they do not employ a 
notion of causation that instantiates regularities ${ }^{3}$. A successful transformation of a nexus of meaning into a causal nexus would have taken place according to this view, and no further argument would be necessary.

However, authors in the interpretivist tradition ${ }^{4}$ claim that reasons differ from causes emphasizing, among other things, that the relation between reasons and actions differs from the relation between causes and effects. More particularly they claim that the relata are logically independent in the latter relation, but not in the former one. This claim has become widely known as the logical connection argument, which stated differently is suggesting that the closer we approach a nomologically tight connection between intention - however this might be specifically defined - and action, the more the statement of this connection assumes the character of a tautology. So, even if an account of singular causation could probably be acceptable on some grounds, a more sophisticated argument is required.

The third step of what I call the "successful transformation argument" is crucial in establishing a transformation of a nexus of meaning into a causal nexus since it is not founded on a notion of singular causation: regardless of the approach and the conceptual apparatus used to apprehend the nexus of meaning of an action, it is always in principle possible that the fundamental elements of this nexus of meaning will also occur in connection with other actions of the same person or of other persons. Every time that one succeeds in identifying similar fundamental elements either in connection with the nexuses of meaning of other actions of the same person or in connection with the nexuses of meaning of the actions of other persons, one has been successful in identifying a regularity. The third step in

\footnotetext{
${ }^{3}$ For a discussion of singular causation see Psillos (2002, chapter 2).

${ }^{4}$ See for example the classical positions of Dray (1957), Winch (1958) and v.Wright (1971). For reviews of the more recent discussions see Little (1991, ch. 4), Kincaid (1996, ch. 6) and Manicas (2006, ch.3).
} 
successfully transforming nexuses of meaning into causal nexuses lies in demonstrating a regularity in the appearance of the fundamental elements in various nexuses of meaning.

In order for my view to be tenable, one need in principle to show that there is at least one standpoint from which a series of nexuses of meaning can be shown to be similar. This is a very reasonable requirement, which is in fact easily met. There is neither in nature nor in the social world (being a part of it) a single repetition, $B$, of a process, A, which is absolutely identical to $A$. All repetitions are merely approximate repetitions, such that $B$ can be more or less similar to $A$, depending on the standpoint from which $A$ and $B$ are viewed. Compare the figures in the following diagram. In this diagram the similarity of certain figures is based on the color, the similarity of certain other figures on the shading, the similarity of others on the interrupted lines that constitute the figures, etc. This diagram illustrates the simple point that things can only be similar in certain respects. 


\section{Diagram}
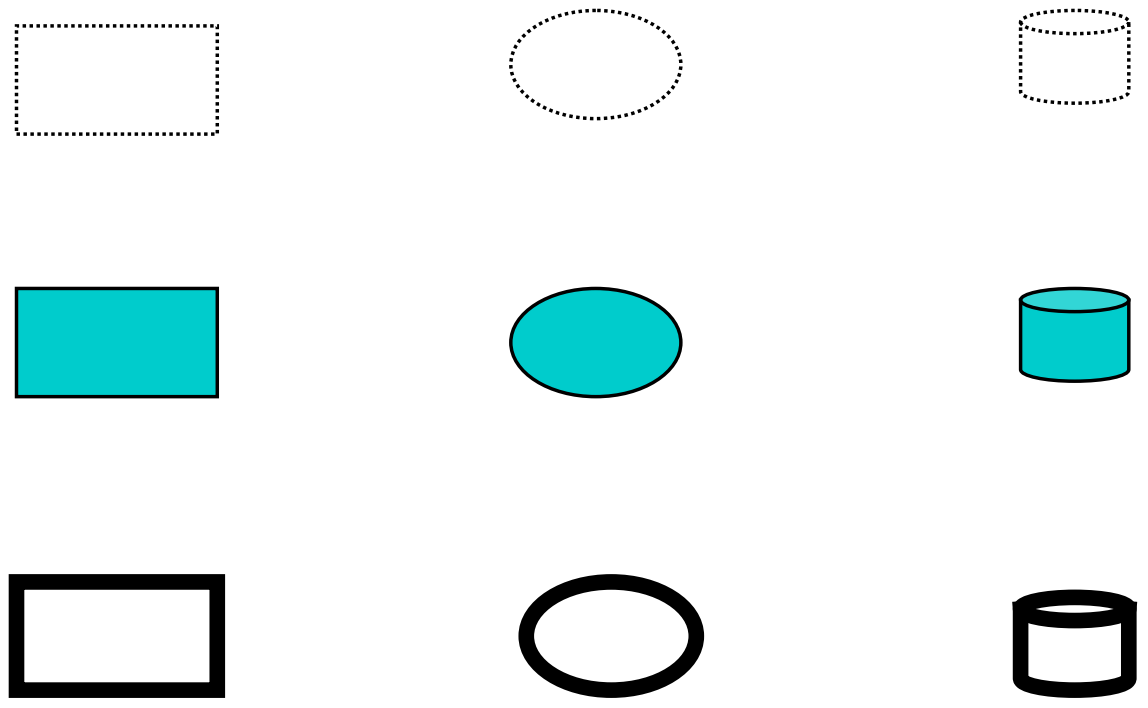

Emphasizing the similarity of two or more things presupposes that one assumes a certain point of view. In our case, the similarity of a series of nexuses of meaning presupposes that one has assumed a certain point of view from which a transformation of nexuses of meaning into a causal nexus is possible. From many other points of view the nexuses of meaning could be more or less dissimilar, but for my argument to hold, it suffices if just one standpoint exists from which such a similarity among nexuses of meaning can be shown. This argument can be best illustrated, I think, with Grünbaum's engaging example in the following quotation:

"[I]t must be pointed out that all particulars in the world are unique, whether they are physical objects like trees, physical events like light flashes, or human beings. The mere assertion that a thing is a particular means that it is in one way or another unique, different from all other objects of its own kind or of other kinds. Every 
insignificant tick of my watch is a unique event, for no two ticks can be simultaneous with a given third event. With respect to uniqueness, each tick is on a par with Lincoln's delivery of the Gettysburg address! It is clear, however, that the uniqueness of physical events does not prevent them from being connected by causal laws, for present causal laws relate only some of the features of a given set of events with some of the features of another set of events. For example, frictional processes are accompanied by the development of heat in so far as they are frictional, whatever else they may be. A projectile fired under suitable conditions will describe a parabolic orbit regardless of the color of the projectile, its place of manufacture, and so on. Since the cause-effect relation is a relation between kinds of events, it is never necessary that all the features of a given cause be duplicated in order to produce the same kind of effect" (1953, p.769).

It is sufficient, thus, for the third step of my argument to be valid, that only one standpoint exists from which nexuses of meaning that arise in connection with a series of actions are shown to be similar in some respect. If this holds, then it is possible to maintain that a regularity of nexuses of meaning has been discovered. I call the repeated occurrence of those fundamental elements - either in the nexuses of meaning connected to numerous actions of a particular person or connected to the actions of different persons - a regularity in human action.

Step four: Regularities, laws and generalizations. The third step of the argument has established the possibility of discovering regularities of nexuses of meaning. The next step of the argument focuses on the statements that describe these regularities. The precise nature of the law-likeness of statements is a difficult problem of the philosophy of science that is not the subject of this paper. I will therefore only show very briefly that even if one is not willing to endow the statements that describe the regularities in the nexuses of meaning with the status of being "laws" and accepts that they are merely "generalizations", one can still provide explanations of meaningful actions. 
According to the traditional notion, only genuine laws allow us to explain and predict the world and to intervene in it (Hempel, 1965). In the tradition of logical empiricism, laws have the following features: logical contingency (they have empirical content), universality (they cover all space and time), truth (they are exceptionless), and natural necessity (they are not accidental) (Mitchell, 2003, p. 130). In accord with this view, a procedure is explained in that the statement that describes it is logically deduced from the conjunction of laws (or law-like statements) and particular statements (initial conditions). In recent decades, however, there have been more and more voices protesting against this traditional view of laws as universal, exceptionless, and necessary, and hence applicable everywhere and for all time. The criticism is not only raised with respect to the laws in the natural sciences (e.g. Cartwright, 1983, 1989), but also with respect to the laws in biology (e.g. Mitchell, 2003) and in the special sciences (e.g. Woodward, 2000). According to this criticism, the traditional criteria for nomological status are either not helpful for understanding what is distinctive about laws or are ideal images that are hardly found when one looks at the actual products of scientific practice. As Mitchell succinctly puts it:

"At one end of the continuum are those regularities, the conditions of which are stable over all time and space. At the other end are the so-called accidental generalizations. And in the vast middle is where most scientific generalizations are found. It is my view that to reserve the title of "law" for just one extreme end is to do disservice to science by collapsing all the interesting variations within science into one category: nonlaws" (2003, p. 138).

According to this alternative to the traditional view of laws then, the statements that describe the regularities in the fundamental elements of the nexuses of meaning constitute "generalizations" rather than genuine "laws". Woodward (2000) also argues that generalizations can in any case function in exactly the same way as traditional laws, helping 
us to explain, and predict the world and to intervene in it. In other words, they help accomplish the same aims in science as the laws have for a long time. Hence, even if one does not want to grant the status of "laws" to the generalizations that describe the different types of regularities of the nexuses of meaning, one can still explain and predict human action- with different degrees of success, of course.

Step five: Regularities, causal ecumenism and explanation. The third step of the argument has established the possibility of discovering regularities of nexuses of meaning. The fourth step has shown that these regularities do not necessarily need to fulfil the criteria of lawfulness postulated by the traditional account of laws as originally formulated by the logical positivists in order to be used for explanatory purposes. Showing this very possibility of existence of regularities with respect to meaningful action is probably the main move against the Interpretivists who have traditionally negated the possibility of existence of such regularity. A famous example is Geertz`s thick description which rejects the possibility of generalizing across cases (1973, pp. 26ff).

In the fifth step I want to address the following question: in order to provide a successful transformation of a nexus of meaning into a causal nexus does one have to be more specific on which regularities are also to count as causal ones? My answer is: for purposes of explanation, no. The study of causation is a huge area to which this paper cannot do any justice anyway. It is generally the case that authors dealing with the problem of causation tend to appeal in their work to quite sophisticated metaphysical machinery trying to specify what a cause consists in exactly, ranging from manipulability to counterfactual dependence and much more 5 "The law of causality", however, as Bertrand Russell has famously stated in 1912, "like much that passes muster among philosophers, is a relic of a bygone age, surviving, like

\footnotetext{
${ }^{5}$ For a critical review of different views of causality see Cartwright (2007, ch.4).
} 
the monarchy, only because it is erroneously supposed to do no harm". Even if one disagrees with Russell and believes that after 100 years the study of causation has indeed stopped doing any harm, it is not necessary to take side on the debate, if the aim is to show that explanations of meaningful actions are possible. I would like, thus, to embrace a causal ecumenism. In other words, I would like to follow the proposal of Michael Strevens at this point (2008, pp.32ff) and do not lose the ecumenical advantage, by adopting a specific theory of causality. Since what Interpretivists doubt is the possibility of providing explanations of meaningful actions, and as I have shown in the fourth step, such explanations do not require strict laws but only generalizations, I would not like my argument to be held hostage to the details of some particular metaphysics of causation ${ }^{6}$.

Since the Interpretivists ' main claim is that the detection of regularities in the social realm is impossible precisely because human actions are unique due to their meaningful character, it is the regularity which is the crux of the matter and not whether a specific regularity is causal or not (following the specific account of causation that one might want to endorse) ${ }^{7}$. I want, thus, in the light of this discussion underwrite a minimalist position and propose that every time that it can be shown that a regularity exists, then Interpretivists have to admit that nexuses of meaning are transformed de facto into causal nexuses. The statements whose content consists in the description of a causal nexus, independently of whether one wishes to call them "laws" or "generalizations", can be used for explanatory purposes. Human actions are subject to

\footnotetext{
${ }^{6}$ That the regularities need to be stable is important in order to be able to use them. If we want to use any generalization we do need to assess their stability, but stability is a gradual criterion, as Mitchell (2009) convincingly shows. All regularities are contingent and historically shaped (also in the physical sciences) and only if contingency is interpreted gradually, as Mitchell does, will our conceptual framework be rich enough to account for the diversity of types of regularities and generalizations.

${ }^{7} \mathrm{Jim}$ Bogen (2005 and 2008) provides an interesting discussion inspired by Anscombe arguing that regularity is one thing and causality another. My purpose, however, is to show the possibility of explanation of meaningful actions. According to the unification account of explanation (Friedman, 1974, Kitcher, 1981, 1989) the notion of causality is altogether avoided anyway and the mechanistic approach of explanation (Machamer, Darden and Craver, 2000, Machamer, 2009 and Bechtel and Abrahamsen, 2005) does also depend on regularities, as Leuridan (2010, pp.321ff) has recently shown quite convincingly. For a discussion of current approaches to explanation in the social sciences see Demeleunaere, $(2010, \mathrm{ch} .1$.
} 
generalizations so that causal explanations of human action are perfectly possible, even if one concedes that human actions are meaningful. And so the main tenet of interpretivism must be considered false.

\section{Conclusion}

Even if one grants the main point of the Interpretivists in the philosophy of the social sciences, i.e. that human actions have meaning, it is possible to show that nexuses of meaning can be successfully transformed into causal nexuses. Independently of the conceptual apparatus that one wishes to use in order to describe a nexus of meaning of an action - be it the motives, the intentions, the reasons, the rationality of the action, or any other means of description - it is always in principle possible that the fundamental elements of a nexus of meaning will also occur in connection with other actions of the same person or of other persons. In those cases in which a regularity in the appearance of the fundamental elements in the different nexuses of meaning can be demonstrated, the nexuses of meaning have been $d e$ facto transformed into a causal nexus. The statements whose content consists in the description of this causal nexus, independently of whether one wishes to call them "laws" or invariant "generalizations", can be used for causal explanations. Hence, causal explanations of human action are perfectly possible, even if one concedes that human actions are meaningful.

It is one main argument of methodological anti-naturalists of all sorts, that searching for explanations in the social realm is not a feasible aim and that the disciplines dealing with the social realm should rather strive for Verstehen (understanding), Interpretation etc. The main thrust of this argument is that the meaningfulness of human actions (constitutive of the social 
realm) does not allow for explanations of the kind provided in the natural sciences. I have tried to show in this paper that as far as the meaningfulness of human action is concerned, this is not a valid claim, and I have provided the "successful transformation argument" in favour of methodological naturalism.

In closing, a final remark must be made in order to avoid misunderstandings. My argument only aims to show that nexuses of meaning can be successfully transformed into causal nexuses and thus nomologically or quasi-nomologically apprehended. However, they need not be. There are moreover many cases in which such a transformation will not be possible, because of the creative character of human nature and for other reasons. In those cases the formulations of generalizations are not possible, and all that one can aim at is an accurate reconstruction of a nexus of meaning of the unique action that is true to the facts, a case that is prevalent in history and other scientific disciplines ${ }^{8}$.

\section{References}

Albert, Hans (1994): Kritik der Reinen Hermeneutik, Tübingen: Mohr Siebeck.

Bechtel, William and Adele Abrahamsen (2005): "Explanation: A Mechanist Alternative", in: Studies in History and Philosophy of Biological and Biomedical Sciences, vol. 36, pp. 421441.

Becker, Gary (1976): The Economic Approach to Human Behavior, Chicago: University of Chicago Press.

Bogen, Jim (2005): "Regularities and Causality: Generalizations and Causal Explanations" in: Studies in History and Philosophy of Biological and Biomedical Studies, vol. 36, pp. 397-420.

\footnotetext{
${ }^{8}$ On this issue see e.g. Mantzavinos (2005).
} 
Bogen, Jim (2008): “Causally Productive Activities”, in: Studies in History and Philosophy of Science, vol.39, pp. 112-123.

Boudon, Raymond (2003): Raison, Bonnes Raisons, Paris: Presses Universitaires de France.

Cartwright, Nancy (1983): How the Laws of Physics Lie, Oxford: Oxford University Press.

Cartwright, Nancy (1989): Nature's Capacities and their Measurement, Oxford: Oxford University Press.

Cartwright, Nancy (2007): Hunting Causes and Using Them, Cambridge: Cambridge University Press.

Davidson, Donald (1963/2001): “Actions, Reasons and Causes”, in: Donald Davidson: Essays on Actions and Events, 2nd Edition, Oxford: Clarendon Press, pp. 3-19.

Demeulenaere, Pierre (ed.) (2010): Social Mechanisms and Analytical Sociology, Cambridge: Cambridge University Press (forthcoming).

Dennett, Daniel (1987): The Intentional Stance, Cambridge/Mass.: The MIT Press.

Dray, William (1957): Laws and Explanation in History, Oxford: Clarendon Press.

Friedman, Michael (1974): "Explanation and Scientific Understanding", in: Journal of Philosophy, vol. 71, pp. 5-19.

Gadamer, Hans-George (1986/1993): Hermeneutik II. Wahrheit und Methode. Ergänzungen und Register, 2nd ed.,Tübigen: Mohr Siebeck.

Geertz, Clifford (1973): The Interpretation of Cultures, New York: Basic Books.

Grünbaum, Adolf (1953): “Causality and the Science of Human Behavior”, in: Feigl, Herbert and Brodbeck, May: Readings in the Philosophy of Science, New York: Appleton - Century Crofts, pp. 766-778.

Hempel, Carl G. (1965): Aspects of Scientific Explanation, New York: Free Press.

Kincaid, Harold (1996): Philosophical Foundations of the Social Sciences, Cambridge: Cambridge University Press. 
Kitcher, Philip (1981): “Explanatory Unification”, in: Philosophy of Science, vol. 48, pp. 507531.

Kitcher, Philip (1989): "Explanatory Unification and the Causal Structure of the World", in: P. Kitcher and W. Salmon (eds.): Scientific Explanation, Minneapolis: University of Minnesota Press, pp. 410-505.

Leuridan, Bert (2010): “Can Mechanisms Really Replace Laws of Nature?”, in: Philosophy of Science, vol. 77, pp. 317-340.

Little, Daniel (1991): Varieties of Social Explanation, Boulder, Colorado: Westview Press.

Machamer, Peter, Lindley, Darden and Carl Craver (2000): “Thinking About Mechanisms”, in: Philosophy of Science, vol. 67, pp. 1-25.

Machamer, Peter (2009): “Explaining Mechanisms”, unpublished manuscript.

Manicas, Peter T. (2006): A Realist Philosophy of Social Science. Explanation and Understanding, Cambridge: Cambridge University Press.

Mantzavinos, C. (2001): Individuals, Institutions, and Markets, Cambridge: Cambridge University Press.

Mantzavinos, C. (2005): Naturalistic Hermeneutics, Cambridge: Cambridge University Press. Mitchell, Sandra (2003): Biological Complexity and Integrative Pluralism, Cambridge: Cambridge University Press.

Mitchell, Sandra (2009): "Complexity and Explanation in the Social Sciences", in: Mantzavinos, C. (ed.): Philosophy of the Social Sciences. Philosophical Theory and Scientific Practice, Cambridge: Cambridge University Press, pp. 130-145.

Psillos, Stathis (2002): Causation and Explanation, Montreal \& Kingston: MacGill-Queen`s University Press.

Russell, Bertrand (1912): "On the Notion of Cause", in: Proceedings of the Aristotelian Society, New Series, vol. 13, pp. 1-26. 
Salmon, Merrilee H. (2003): “Causal Explanations of Behavior”, in: Philosophy of Science, vol. 70, pp. 720-738.

Searle, John (2001): Rationality in Action, Cambridge/Mass.: The MIT Press.

Searle, John (2009): “Language and Social Ontology”, in: Mantzavinos C., (ed.) Philosophy of the Social Sciences, Cambridge: Cambridge University Press, pp. 9-27.

Strevens, Michael (2008): Depth. An Account of Scientific Explanation, Cambridge, Mass.: Harvard University Press.

Taylor, Charles (1985): Philosophy and the Human Sciences, Philosophical Papers, vol. 2, Cambridge: Cambridge University Press.

Von Wright (1971): Explanation and Understanding, Ithaca, New York: Cornell University Press.

Weber, Max (1922/1985): Gesammelte Aufsätze zur Wissenschaftslehre, (ed.) Johannes Winckelmann, 6th rev. edition., Tübingen: Mohr Siebeck.

Winch, Peter (1958): The Idea of a Social Science and its Relation to Philosophy, London: Routledge \& Kegan Paul.

Woodward, James (2000): "Explanation and Invariance in the Special Sciences", in: British Journal for the Philosophy of Science, vol. 51, pp. 197-254.

Woodward, James (2003): Making Things Happen, Oxford: Oxford University Press. 